\title{
O CUIDADO DE SI NA SAÚDE: um olhar pedagógico sobre o outro e sobre o mundo. ${ }^{1}$
}

\section{Care for health: a pedagogical look at the other and the world.}

\author{
Felipe Gustavo Soares da Silva²
}

RESUMO: O presente trabalho trata de refletir sobre o cuidado de si na saúde desde o ponto de vista individual de cada sujeito da sociedade até o profissional em saúde que cuida de si e dos outros. O cuidado será antes de tudo uma atitude pedagógica que faz bem ao homem, ao outro e ao mundo.

Palavras-chave: Cuidado de si. Sáude. Coletividade. Cuidado do outro.

ABSTRACT: The present work tries to reflect on the care self in the health from the individual point of view of each subject of the society until the health professional that takes care of itself and of the others. Care will be, above all, a pedagogical attitude that is good for the man, the other and the world.

Keywords: Care of you. Cheers. Collectivity. Care of the other.

\section{INTRODUÇÃO}

O tema do evento "Estratégias para o enfrentamento das doenças tropicais e negligenciáveis," parece-nos um tanto sugestivo para falarmos de cuidado nas relações que envolvem a prática e a vivência do ser humano em torno das questões que envolvem sua própria conservação no mundo, noutras palavras, sobre a saúde do homem como responsabilidade dele mesmo.

Que tipo de estratégias podemos, em nível pessoal e ao mesmo tempo coletivo, empreender em prol do avanço da prevenção e tratamento em certos tipos de doenças? Sem dúvida, há recursos que são destinados para pesquisa e tratamento porém, o que nós podemos fazer aqui, no nosso espaço particular de vida, de habitação, de convivência social? Olhar para si mesmo como responsável pela saúde do meu próximo, ensinar e aprender a cuidar, isto é o que chamamos

\footnotetext{
${ }^{1} \mathrm{O}$ texto é fruto de palestra no IV encontro internacional multiprofissional em saúde e IV congresso em práticas para a educação em saúde (IV CIMS-PE) onde participamos do GT Educação e saúde e tivemos a oportunidade de refletir do ponto de vista filosófico sobre práticas pedagógicas em saúde.

${ }^{2}$ Mestre em Filosofia pela UFPE. Especialista em educação, pobreza e desigualdade social pela UFPE.
} 
olhar pedagógico, que envolve um aprendizado e um ensino mútuo, uma relação de abertura ao outro a partir de si mesmo e da reflexão que cada um faz de si e de sua contribuição para o outro.

Este termo pedagógico faz-nos voltar à antiguidade e rever o tema do cuidado como uma máxima e uma prática presente na cultura grega. Aprendia-se na Paideia grega, a cuidar de si e esse aprendizado era a base da educação na antiguidade. Cuidar de si implicava um modo de vida que formasse o homem e possibilitasse 0 alcance da Arete (Excelência). A principal expressão de cuidado na antiguidade era a moderação: o grego não se preocupava com o que se comia ou bebia, não se preocupava com o sexo nem com quem se fazia o sexo, mas com o modo e a quantidade do que era feito, ingerido ou bebido. $O$ objetivo do grego era evitar a desmedida (Hybris).

Neste sentido, a questão do cuidado de si e seu plano de fundo histórico revela o cuidado com o corpo através do conceito de moderação que forneceria ao homem uma maneira razoável de lidar consigo mesmo e com seus apetites de maneira que suas próprias ações não lhe privassem nem da vida política nem da arete.

Em nossa experiência acadêmica, estudamos oportunamente estas questões do cuidado voltadas para a sexualidade humana, agora, de maneira mais geral, acreditamos o debate filosófico aplicado á área da saúde possibilita um campo fértil de reflexões sobre o quão importante é a atitude do próprio homem no processo de sua conservação, pela consciência de si no mundo e em relação com os outros. A atitude de cuidado consigo será aqui defendida como um ato que envolve e desdobra-se pelo cuidado com o mundo e com os outros, que também estão no mundo.

Cumpre dizer que a primeira forma de relacionamento humano é por um ato de cuidado. Um cuidado que não é mais de si mais do outro: quando estamos no ventre de nossa mãe, somos objeto de cuidado, a mãe cuida de si e do filho, o outro. Quando nascemos, um médico cuida de nós, enfermeiras, toda uma equipe, mas sobretudo, nossa mãe cuida em nos alimentar. Parece-nos que somos seres do cuidado, e cuidamos uns dos outros quando reconhecemos que o outro é dependente de nós. $O$ texto tenta chamar atenção para o fato de que como mães devemos cuidar uns dos outros e como filhos, precisamos do cuidado dos outros e precisamos de um ambiente no qual possamos viver bem. 
Encontramos na ética do cuidado, sobretudo, a partir de sua fundamentação histórica, um aporte teórico que, a partir da crítica filosófica, nos possibilita refletir sobre que ação estamos adotando, individualmente, quando o assunto é a nossa própria conservação no mundo. Desta maneira, acreditamos e enxergamos na ética do cuidado uma alternativa para o debate e a formação também dos profissionais da área da saúde; a ética do cuidar ao invés de uma ética normativa parece-nos uma boa oportunidade em dialogar sobre uma ética profissional aplicada a partir dessa abordagem histórico-prática da ética do cuidado.

A prática do profissional de saúde não escapa nossa reflexão verificando o cumprimento da ética do cuidado no exercício e no trato com os pacientes. Os profissionais são "mães" por excelência no trato e na obrigação do cuidar. Porém a abordagem que damos ao problema aqui vai um pouco além de examinar práticas apenas do profissional no exercício de sua profissão. Analisamos também a dimensão política em que o cuidado de si aplicado à saúde revela em sua essência e apresenta como uma atitude do homem em relação ao outros homens.

Para tanto, o processo pedagógico (GALLO, 2006) de educar o homem a cuidar de si mas também do outro e do mundo não dispensa a ajuda desses profissionais que dia a dia lidam com as pessoas, formam opinião e sobretudo movem as pessoas pelos exemplos.

Apesar de uma grande quantidade de trabalhos já na área de saúde atualmente, sobre o tema do cuidado, nossas palavras aqui se iniciam em tentar introduzir o leitor a conhecer a problematização no plano histórico da ideia de cuidado, seu avanço para o cuidado de si e seu desdobramento para o cuidado com o outro: cuidar de si implica e inclui um cuidar do outro e consequentemente do mundo em que vivemos. Essa relação tão importante, todavia, só é possível por um olhar pedagógico, ou seja, pela educação do homem, como faziam os antigos e já que 0 evento reflete sobre estratégias de enfrentamento para o problema das doenças, é que propomos um trabalho de conscientização de algo básico mas que as vezes passa impercebível aos olhos dos homens: ele está no mundo e não está só e precisa entender que é por toda vida mestre e aprendiz do cuidado, que é eticamente responsável pelo bem e pela saúde do outro, assim como a felicidade de um todo. São estes os elementos que pretendemos discutir e apresentar a partir de um possível diálogo entre a Filosofia e ética do cuidado aplicada à enfermagem. 


\section{A NOÇÃO DE CUIDADO DE SI}

O cuidado de si, noção importantíssima do mundo antigo, trata-se de uma série de práticas que conduzem o homem a uma cultura de si mesmo, a uma vigilância sobre suas ações e uma contínua reflexão sobre elas, que tem como finalidade última para a vida humana o alcance da Excelência.

$\mathrm{Na}$ história da Filosofia há algumas concepções de cuidado que aqui trazemos para elucidar o pensamento sobre o tema do conforme queremos abordar: Platão, discípulo de Sócrates ${ }^{3}$, no diálogo Alcibíades primeiro define o cuidado de si - epimeleia heautou - como o cuidado da alma visando um governo de si e conhecimento de si como fundamento e condição preliminar para governar a cidade. (PLATÃO, 2007) No pensamento de Heidegger o tema do cuidado - sorge - aparece numa noção não tão distinta mas liga-se ao ser do homem no mundo - dasein uma reflexão existencial sobre a própria existência do homem no mundo e em relação com os outros. (HEIDEGGER,1972). Não se trata de uma dimensão pedagógica-formativa como na antiguidade mas existencial. A reflexão de $M$. Foucault é a que engloba não só uma reflexão do conceito mas uma análise histórica desde o momento pré-filosófico até a contemporaneidade. Foucault definirá o cuidado como uma forma do homem olhar para ele mesmo e ter uma atitude diante de si mesmo (FOUCAULT, 2014, p.14-15).

Em seu segundo volume da História da Sexualidade, Foucault aborda em um capítulo específico onde ele chamada de uso dos prazeres a forma pela qual o homem antigo relacionava-se com seus desejos e as práticas ou o uso que faz deles (FOUCAULT,1998). Já no recuo histórico ao mundo grego, realizado em sua Hermenêutica do sujeito, descreve o que seria o cuidado de si, e em que consistem as diversas ações praticadas pelo homem grego; mesmo não se tratando de uma análise técnica da obra platônica, mas uma análise da questão do cuidado diante do que ele chama de "tecnologias de si', Foucault traz uma análise importante para que possamos conceituar o cuidado de si como modo de viver dos gregos:

\footnotetext{
${ }^{3}$ Sócrates não tem nenhuma obra escrita mas seu testemunho filosófico chega até nós por seus discípulos especialmente por Platão. O cuidado em Sócrates é atribuído a um cuidado da alma, ou Psiche. Este cuidado é testemunhado diretamente em um diálogo de Platão chamado apologia de Sócrates.
} 
Primeiramente, o tema de uma atitude geral, um certo modo de encarar as coisas, de estar no mundo, de praticar ações, de ter relações com o outro. A epimeléia heautou é uma atitude para consigo, para com os outros, para com o mundo. Em segundo lugar, a epimeléia heautou é também uma certa forma de atenção, de olhar. Cuidar de si mesmo implica que se converta o olhar, que se o conduza do exterior para...eu ia dizer "o interior"; deixemos de lado esta palavra (que, como sabemos, coloca muitos problemas) e digamos simplesmente que é preciso converter o olhar do exterior, dos outros, do mundo, etc. para si "mesmo". O cuidado de si implica uma certa maneira de estar atento ao que se pensa e ao que se passa no pensamento. Há um parentesco da palavra epimeléia com meléte, que quer dizer ao mesmo tempo, exercício e meditação. Em terceiro lugar, a noção de epimeléia não designa simplesmente esta atitude geral ou esta forma de atenção voltada para si. Também designa sempre algumas ações, ações que são exercidas de si para consigo, ações pelas quais nos assumimos, nos modificamos, nos purificamos, nos transformamos e nos transfiguramos. Daí uma série de práticas que são, na sua maioria, exercícios, cujo destino (na história da cultura, da filosofia, da moral, da espiritualidade ocidentais,) será bem longo. (FOUCAULT, 2014, p.14-15)

Nos seus estudos, Foucault trata de examinar a noção de cuidado apontando três dimensões principais em que o cuidado de si relaciona-se: primeiramente a pedagogia, depois a política, e por fim a erótica (FOUCAULT, 2014, p.52). O autor centraliza sua abordagem ao cuidado de si numa obra chamada Alcebíades primeiro, onde analisa o cuidado da alma como principal objetivo do diálogo entre Sócrates e o jovem Alcibíades. O estudo realizado por Foucault não pode ser desprezado visto sua atualidade e significação para o estudo atual da noção do cuidado e visto sua descrição sobre o que significavam as diversas práticas vividas e compartilhadas pelo homem grego, porém Foucault não pretendeu rever os gregos, mas observar os modos de constituição do sujeito (moderno) noção totalmente distinta do mundo antigo (DELEUZE, 1996, p.115).

Portanto, a preocupação do homem grego era, na verdade, não com aquilo com o qual ele se relacionava, mas em que medida se dava essa relação, em que intensidade o homem sabia lidar com os seus desejos e apetites, sejam eles de qualquer tipo e como havia de satisfazê-los de forma que não fosse a eles submisso, mas senhor, e tudo isso reforça a ideia que deu início a este ponto específico do trabalho: de fato, a filosofia grega era uma filosofia voltada e aplicada à vivência do próprio homem de maneira a estabelecer a maneira mais perfeita e mais excelente de viver, ou seja, era uma preocupação com o aspecto qualitativo do relacionamento humano. 


\section{O AUTOCUIDADO E O CUIDADO DE SI: SAÚDE E FILOSOFIA}

A saúde é um tema filosófico e isto podemos encontrar nos mais primórdios períodos da Filosofia grega: Segundo o estudo de JAEGER (2011) é no contato com a Filosofia que a medicina adquire um status cultural explicando-se assim a posição social do médico, ao lado do ginasta como responsáveis pela cura e conservação da saúde do corpo. A relação é explicitada sobretudo em Platão, um dos maiores defensores do pensamento Socrático que a Tradição filosófica trouxe até nós. No Banquete, um diálogo de Platão sobre o amor, os convivas do banquete antes de fazerem seu discurso sobre o amor são instigados e recomendados pelo médico Erixímaco a não beberem (PLATÃO, 2011, p.85), ou que façam com moderação, e este é o acordo das personagens. A moderação do não beber representa a nosso ver uma prática de cuidado de si no Banquete de Platão que reflete e exemplifica o cuidado de si como uma prática do homem grego. ${ }^{4}$

Dialogando com a área de saúde, lançamos olhar sobre o conceito de autocuidado de Doroteia Orem (1914-2007), visto a teoria estabelecer um sistema que visa organizar as práticas de enfermagem a partir da reflexão sobre as práticas que o sujeito faz sobre si mesmo. Pretendemos verificar se há e uma relação entre a prática de cuidado e a teoria do autocuidado na enfermagem, buscando encontrar aproximações entre Filosofia e prática de saúde neste caso específico.

O termo autocuidado foi mencionado pela primeira vez em 1958 por Doroteia Orem em suas reflexões sobre como e porque os indivíduos necessitam ser ajudados pela enfermagem, elaborando assim uma teoria do autocuidado aplicada à observações na prática da enfermagem. Esta teoria de autocuidado (OREM,1980) compreende outras três que se inter-relacionam e aplicam-se ao tema do cuidado na enfermagem, a saber a teoria dos sistemas de enfermagem, o déficit do autocuidado e o auto cuidado; O autocuidado descreve a prática de cuidados realizados pela pessoa portadora que necessita manter a saúde. $O$ déficit de autocuidado delineia a necessidade da assistência de enfermagem. O sistema de enfermagem explica como as pessoas são ajudadas por meio da enfermagem e este é um ponto peculiar

\footnotetext{
${ }^{4}$ Ver sobre o assunto nosso estudo DA SILVA, F.G.S. Práticas de cuidado de si nas cenas iniciais do Banquete de Platão. Cadernos Cajuína, V. 1, N. 1, 2016, p. 32 - 39 ISSN: 2448 - 0916.
} 
da teoria de OREM que acreditamos que pode nos servir de ponte para dialogarmos com o conceito de cuidado de si.

Orem determina ações específicas para a prática de enfermagem que nos lembra a responsabilidade pelo outro a ética do cuidado defende. Ao mesmo tempo em que cuida do outro, o profissional de saúde ensina-o a cuidar e buscar esse cuidado. Parece-nos uma maneira bem fiel de corresponder ao apelo ético do cuidado em estreitar as relações entre os seres humanos pela responsabilidade do bem do outro e que esse outro procure esse bem, neste caso, a saúde.

De acordo com a teoria do autocuidado, importante aqui para esse nosso estudo, o homem tem uma capacidade de refletir sobre si mesmo, sobre seu meio e criar para isso mecanismos e símbolos na comunicação, que façam bem a si mesmos e aos outros. As ações humanas apontadas pela teoria recomendam tratam de acordar meios de atender às necessidades do autocuidado, desenvolver novas técnicas para o autocuidado; revisar a rotina do dia a dia, promover o enfrentamento dos efeitos do desvio da saúde ou da terapêutica médica, dentre outras práticas.

A autora descreve o que seria o autocuidado explicando que o autocuidar é uma atitude aprendida e direcionada para um objetivo: o bem da pessoa e sua saúde. Ora, a autora destaca que é próprio do ser humano fazer o autocuidado, neste sentido, parece que podemos dialogar com o panorama histórico do cuidado na questão de que o indivíduo é o principal autor desta atitude. Parece-nos que encontramos aqui um diálogo entre o cuidado e o autocuidado quando o sujeito humano tem as possibilidades e o potencial de cuidar de si próprio e promover o próprio bem.

No campo prático da relação destas teorias, encontramos o elemento do aprendizado sobre o cuidar que norteia as duas teorias: no cuidado de si aprende-se a cuidar com um mestre que é o outro e que por sua vez já está num estágio mais profundo do ciclo de cura que é a responsabilidade pelo cuidado que o outro tem de si mesmo. Essa responsabilidade, diríamos, é a premissa da ação profissional na área de saúde, não basta apenas prestar o atendimento mas é necessário convencer e ensinar ao doente a cuidar dele mesmo.

Cuidado de si e autocuidado se entrelaçam, um pelo aspecto racional e reflexivo que apela ao ser humano o desenvolvimento e o exercício daquilo que tem de mais especial e único: a racionalidade. O outro como apelo e objetivo educativo da prática de profissionais. Cuidar de si ou autocuidar-se representa uma ação 
forma o sujeito no mais íntimo de seu ser, de sua completude e o condição no mundo pela relação com o outro.

Ao mesmo tempo, cuidar de si ou autocuidar-se é considerar o outro como fundamental nas diversas relações humanas: é o outro o modelo de cuidado, é o outro o paradigma, o referencial, o tutor, o mestre e principalmente, o elemento que garante que o meu cuidado seja efetivo, ao mesmo tempo, e não menos importante, o outro representa a alteridade por trás do cuidado: quando cuido de mim ofereço ao outro o melhor possível, somos seres sociáveis, ninguém vive sozinho e isolado, mas enquanto seres políticos, é no meio social que exerço meu papel curativo de olhar para o outro aprendendo e ensinando a cuidar: somos, portanto, modelos e aprendizes do cuidado. Ao mesmo tempo, quando cuidamos do outro é de nós mesmos que cuidamos porque preparamos para nós o melhor e garantimos que ele nos dê o que há de melhor em si.

O profissional em saúde cuida dos outros e mantém vivo a chama social da relação embasada numa troca de ações comunitárias. Eu cuido, enquanto médico, por exemplo, do professor, do advogado, do juiz, do policial, e o bem estar de cada um deles garante o meu também, a partir da realização e do exercício de cada um deles, um bem coletivo.

A responsabilidade do cuidar parece aqui como uma atitude comum a todos mas pesa sobre o profissional de saúde o status do "conhecimento de causa," a autoridade em responder corretamente pelo assunto. O tema normalmente gira em torno de saúde porém se cuida muito mais do que só a saúde; cuida-se por exemplo de adquirir conhecimentos estudando, cuida-se do espiritual dedicando-se tempos em igrejas, templos ou até mesmo preocupando-se em negar ou duvidar a existência de divindades que interfiram no mundo humano, porém a saúde ainda aparece como o elemento base para qualquer ação de cuidado: o que queremos antes de qualquer coisa é a saúde. Parece que há aqui, uma demonstração de que há uma hierarquia entre os objetos de cuidado. Enquanto o cuidado de si, busca a formação e a excelência do homem como um todo, o autocuidado, de acordo com Orem, parece prezar pelo cuidado da saúde, e não seria diferente visto estarmos examinando esta dimensão do cuidado de si. Quanto à relação saúde-pensamento podemos afirmar com o autor que 
Os curadores (médicos) são auxiliares de um processo que o sujeito deve conduzir junto com seu corpo e seu ambiente; é por isso que "o médico que por sua vez é filósofo (amor à sabedoria) é igual aos deuses", os quais são os guias do sujeito. A responsabilidade da pessoa quando à sua saúde é bem nítida: "faça do teu alimento o teu remédio", "cura-te a ti mesmo" (Hipócrates). Enfim, saúde no sentido maior, leva à medida, ao equilíbrio e, assim, ao Bem e à contemplação do Belo, em meio ao Pathos (sofrer, sentir, paixão). (PELIZZOLI, 2013, p.20)

Cuidar de si mesmo significa, na dimensão medicinal do cuidado, cuidar da saúde e do bem estar de si e dos que estão comigo também. O profissional cuida e tenta garantir que outras pessoas cuidem de si, como falamos, num âmbito social, podemos concluir que o cuidado médico é um cuidado de si pelo cuidado do outro e está intimamente relacionado com o cuidado de si no seu mais antigo e original conceito.

\section{IMPLICAÇÕES DO CUIDADO DE SI NA SAÚDE: DESDOBRAMENTOS}

Longe de ser uma prática individualista, o cuidado de si é uma prática que envolve o outro como objeto ao qual se dirige o meu cuidado, e neste sentido, a noção de cuidado como espiritualidade ganha força no sentido de que deve ser algo que vem "de dentro" do próprio homem mas que não fica em si, dirigindo-se para o outro que colhe os frutos desta atitude. O cuidar do ambiente em que se vive não se enquadraria numa prática que vai do individual ao coletivo pela ação de cuidado?

Se voltarmos ao mundo antigo, vemos a noção de cuidado como elemento politico, no sentido de que sua ação reflete no todo de uma comunidade. Falamos disso logo acima. O cuidado de si nunca é só de si mas do outro também, mostra preocupação, compromisso, responsabilidade com o todo. $\mathrm{O}$ trabalho individual e a conscientização são ações práticas do individual ao coletivo. Quando se preocupa consigo, na verdade, é do outro que se cuida, e isso representa um ciclo, um tanto difícil de encontrar no mundo de hoje, onde o individualismo parece uma situação mais confortável para que os homens "sentem-se e durmam" o sono do individualismo.

As recentes pesquisas e diversos trabalhos que traduzem as preocupações dos nossos dias com as doenças ocasionadas pelo Aedes aegypti são exemplos das práticas de cuidado com o outro, a um nível coletivo, e que devem ser cada vez mais 
exploradas e incentivadas pelos que detém o poder de governar. Ademais, a prática individual de cada membro da sociedade em cuidar do ambiente de forma preventiva representa um cuidado para si e para os outros.

\section{O CUIDADO COM O MUNDO: “O SI” E O “OUTRO” JUNTOS}

Ora, o cuidado enquanto práticas do indivíduo para consigo mesmo através de um agir refletido, seja conforme praticado no mundo e no pensamento grego, seja na atualidade por meio de uma relação social, pode ser trazida aqui como ume elemento importante como boa regra de convivência e de autoconservação da própria espécie humana.

O cuidar de si, pode então representar, a partir de uma prática extremamente coletiva, pela prática individual, uma atitude de responsabilidade social. Note-se que aqui propomos que essa responsabilidade social pode ser teorizada a partir de uma cultura antiga mas com características que não desaparecem com o tempo. $O$ cuidado do outro e do mundo em que se vive parte da minha conscientização sobre como viver nesse mundo e de modo coletivo, e, ainda mais, de cuidar desse mundo sendo então este mundo cuidado uma dádiva que eu entrego ao outro pela minha responsabilidade social.

Apesar de um tanto de práticas advindas de campanhas do governo, parecenos que ainda falta o cuidado do outro nas ações individuais. Ainda vemos uma quantidade significável de situações onde o descaso é individual, onde a falta de cuidado consigo mesmo e com sua saúde, neste caso específico, acaba representando tanto uma falta de cuidado com o outro como uma falta de cuidado com o ambiente em que se vive. Ora, uma simples ação dentro de casa ou ao redor da casa, pode salvar vidas inclusive a própria. Mas até que ponto está o homem a cuidar dos outros e do seu mundo?

\section{CONCLUSÃO}

Cuidado e autocuidado andam juntos seja na reflexão filosófica seja na proposta de ação para a enfermagem pelo fato de ambos, como elementos próprios da Epimeleia heautou, do cuidado de si porém este trabalho nos leva a 
compreensão de que o autocuidado assim como o cuidado de si, situando este último na Paideia antiga, são elementos práticos porém aprendidos, daí a ideia de uma pedagogia do cuidado.

A dimensão pública do cuidado ressalta a importância que enquanto cuido de mim mesmo assumo a responsabilidade de cuidar do outro dando a ele a melhor condição de convivência e, ao mesmo tempo, me torno modelo de cuidado para o outro. Quando cuido de mim mesmo não é só de mim que cuido mas do outro; quando aprendo a cuidar de mim me insiro num ciclo de cuidado do qual quem me ensinou já faz parte. É um ciclo que nunca morre mas sempre reúne sujeitos desta educação.

Quando cuido do outro é de mim mesmo que estou cuidando, garantindo o melhor para o outro que irá conviver comigo, é o meu "próximo" que está sendo objeto de cuidado, objeto direto e não indireto: o cuidado nunca é individual mas coletivo.

Quando cuido do mundo, preservo, conservo, protejo e tomo ações que garantem a saúde e o bem estar da sociedade como um todo estou cuidando de mim mesmo e de toda uma descendência que deriva-se de mim e convive comigo. Antes de fazer as grandes coisas, devemos olhar para o mundo em que vivemos. Será que estamos cuidando do nosso meio ambiente ou contribuindo para sua degradação? Cuidar de si vai muito de conhecer-se e praticar boas ações para si mesmo, mas desdobra-se, portanto, para o cuidado do mundo no qual as outras pessoas estão inseridas e novas pessoas virão a dar continuidade neste processo.

O profissional de enfermagem carrega, portanto, uma missão não só de cuidar da saúde dos outros mas de ensiná-los que esse cuidado desdobra-se e é uma responsabilidade que assumo a partir do momento que vivo em sociedade, no ambiente político, em meio a outros homens. É tarefa também dos professores em todos os níveis de escolaridade transmitir aos seus alunos essa mensagem porém parece-nos que quando o profissional de saúde alerta sobre ações práticas de cuidado com o meio em que se vive ascende-se uma luz sobre a mente dos seres humanos em enxergar todas as possibilidades de desgraças caso o cuidado não aconteça. $\mathrm{O}$ autocuidado parece-nos que é um conceito que traz de maneira mais traduzida e clara para cada homem a responsabilidade que ele tem de se proteger contra aqueles que não cuidam nem de si nem do mundo; ao mesmo tempo, o autocuidado garante uma espécie de proteção contra os desvios e déficits das 
práticas de cuidado. Tudo isso nos leva a concluir que, juntos, a educação e a saúde, enquanto áreas de persuasão intelectual devem alertar cada vez mais os homens para o compromisso social e a responsabilidade de aprender a cuidar e por em prática esse aprendizado, tendo então um mundo não somente mais saudável mas também mais consciente de como fazer para que nos tornemos saudáveis de corpo, alma e convivência, uns aos lados dos outros, aproveitando o que de melhor a vida nos oferece, o próprio viver e o desfrutar da presença do outro ao nosso lado.

\section{REFERÊNCIAS}

BELLOUR, Raymond. Um devaneio moral. In: ESCOBAR, Carlos Henrique de. (Org.). Michel Foucault: O dossiê - últimas entrevistas. Rio de Janeiro: Taurus, 1984.

CHINN, P.; Kramer MK. Theory and nursing: a systematic approach. Missouri: Mosby; 1995.

JAEGER, Werner. Paideia: a formação do homem grego. 5a edição. São Paulo: Martins fontes. 2011.

DANNER, F. Cuidado de si e estética da existência em Michel Foucault.

Filosofazer. Passo Fundo, n. 32, jan./jun. 2008, p. 73-94.

DA SILVA, F.G.S. Práticas de cuidado de si nas cenas iniciais do Banquete de

Platão. Cadernos Cajuína, V. 1, N. 1, 2016, p. 32 - 39 ISSN: 2448 - 0916.

DELEUZE, G. Conversações. Rio de Janeiro: Editora 34, 1996.

FAWCETT J. Contemporary Nursing Knowledge: Analysis and Evaluation of Nursing Models and Theories. 2nd ed. Philadelphia (PA): F. A. Davis Company; 2005.

FONSÊCA A. O cuidado transpessoal de enfermagem domiciliar ao portador de transtorno mental e sua família: uma contribuição para a reinserção social [dissertação]. Curitiba (PR): Universidade Federal do Paraná; 2004.

FOUCAULT, M. A hermenêutica do sujeito. Trad. de Márcio Alves da Fonseca; Salma Tannus Nuchail. São Paulo: Martins Fontes, 2014.

GALLO, Silvio. Cuidar de si e cuidar do outro. In: W. O. Kohan, \& J. Gondra. Foucault 80 anos (pp.177-190). Belo Horizonte: Autêntica, 2006.

GRABOIS, P. F. Sobre a articulação entre cuidado de si e cuidado dos outros no último Foucault: um recuo histórico à antiguidade. Ensaios filosóficos. v. 3, p. 105-120, abril de 2011. 
GROS, Frédéric. Situação do curso. In: FOUCAULT, Michel. A Hermenêutica do sujeito. São Paulo: Martins Fontes, 2004.

HEIDEGGER, Martin. Sein und Zeit. Tübingen: Max Niemeyer, 1972.

LUNARDI V. A governabilidade na enfermagem: do poder pastoral ao cuidado de si [tese]. Florianópolis (SC): UFSC/PEN; 1997.

MUCHAIL, S. T. Foucault, mestre do cuidado: textos sobre hermenêutica do sujeito. São Paulo: Edições Loyola, 2011.

NUNES, Benedito. Heidegger e Ser e Tempo. Rio de Janeiro: Zahar, 2002.

OREM Debora. Nursing: concepts of practice. New York: McGrau-Hill; 1980

PAGNI, P. A. O cuidado de si em Foucault e as suas possibilidades na educação: algumas considerações. In L. A. Souza, T. T. Sabatine, \& B. R. Magalhães (Orgs.). Michel Foucault: sexualidade, corpo e direito. (pp. 19-46). Marília: Oficina Universitária; São Paulo: Cultura Acadêmica, (2011).

PELIZZOLI, Marcelo L. Ética e meio ambiente. Petrópolis: Vozes, 2013.

A emergência do paradigma ecológico. Petrópolis: Vozes, 1999.

PLATÃO. Simpósio. Tradução de Carlos Alberto Nunes. - $3^{a}$ ed. - Belém: ed. UFPA 2011.

. O primeiro Alcibíades. In. Fedro, Cartas, o primeiro Alcebíades. Trad de Carlos Alberto Nunes. Belém: UFPA, 2007. 